\title{
Pitfalls for Japanese Specialists in English Technical Writing
}

\section{Yoshiaki Shinoda}

\begin{abstract}
In order to correctly and concisely understand a scientific, technical English article written by a Japanese specialist, the readers should understand in what areas of English grammar they are inclined to make mistakes when they write an English version. The most crucial mistakes made are usually certain aspects of English grammar. Learning the key mistakes from a Japanese specialist will also help an English teacher focus more efficiently on profitable areas of teaching.
\end{abstract}

The rapid and immense increase in technical intercommunication using English, calls for intense and interesting research into an area of language study which we call " English for Science and Technology" (EST). Especially in Japan, the number of specialists dealing with EST has been increasing enormously. Japanese scientists and engineers attempting to read and write EST, however, are almost always lacking in the understanding of how syntactic structure reflects content or conceptual structure since English is a second or foreign language to Japanese and the language structures of English and Japanese differ completely. How the syntactic structure affects comprehension is critically important to Japanese scientists and engineers. I therefore have taken an interest in the correlation between syntax and content in EST and have been exerting all possible efforts in order to find clues as to what grammatical points Japanese specialists should most 
effectively comprehend to understand English contexts.

Having taught EST in Japan for over fifteen years, I can say that the fundamental problems that most Japanese scientists and enginners, as well as students in such fields, are facing in EST, can be roughly classified as follows:

1. They have not mastered the proper use of

1.1. articles

1.2. tenses

1.3. auxiliary verbs

1.4. subjunctive mood

1.5. prepositions

2. They often use inappropriate words :

2.1. improper adjectives

2.2. unsuitable subject noun and predicate verb

Let me explain briefly from 1.1.

\section{1. Articles}

Consider the following four structurally similar sentences:

i. A neon lamp is an electronic tube.

ii. The neon lamp is an electronic tube.

iii. Neon lamps are electronic tubes.

iv. The neon lamps are electronic tubes.

To native English speakers, such differences may be unimportant; however, to the people who are learning English, especially, specialists, an explanation of such examples is critical to the correct understanding of the contexts. When an adjective, such as "complicated," is placed in front of "electronic tube," which sentences among the following four would be appropriate?

$\mathrm{i}^{\prime} A$ neon lamp is a complicated electronic tube.

ii $^{\prime}$ The neon lamp is a complicated electronic tube.

iii' Neon lamps are complicated electronic tubes.

iv' The neon lamps are complicated electronic tubes. 


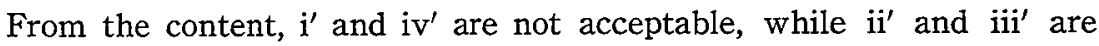
acceptable. However, when we interpret iv' as specified neon lamps, it can be accepted as a matter of course. If all neon lamps are simple electronic tubes, the following four sentences will be acceptable.

$\mathrm{i}^{\prime \prime} A$ neon lamp is a simple electronic tube.

ii" The neon lamp is a simple electronic tube.

iii" Neon lamps are simple electronic tubes.

iv" The neon lamps are simple electronic tube.

From the above examples, we find the articles have extremely important relationship with modifiers. Japanese people cannot easily understand in what situations the above four would be used.

\subsection{Tenses}

English has six tenses such as future, future perfect, present, present perfect, past, and past perfect, while the Japanese language generally has only three: future, present, and past. For the Japanese people, therefore, the following sentences reflect the same meaning.

i. We developed a new device suitable for the equipment.

ii. We have developed a new device suitable for the equipment.

iii. We have been developing a new device suitable for the equipment. In EST these three have important differences in meaning, but when translated into Japanese uncircumlocutionally, these are expressed in the same syntactical and conceptual structures. The difficulties and misunderstanding, therefore, appear when the equivalent Japanese is translated into English. In a mechanical translation from Japanese into English, the English version will be conceptionally different from the original Japanese text. You will probably and often notice the present perfect tense tends to conceal itself in English sentences written by Japanese.

\section{3. Auxiliary verbs}

The Japanese language has less auxiliary verbs than English, which causes Japanese specialists difficulties in using and under- 
standing these verbs.

i. A single dry-cell operates the clock accurately for one full year.

ii. A single dry-cell can operate the clock accurately for one full year.

iii. A single dry-cell may operate the clock accurately for one full year.

iv. A single dry-cell could operate the clock accurately for one full year.

v. A single dry-cell might operate the clock accurately for one full year.

vi. A single dry-cell would operate the clock accurately for one full year.

Structurally, the above sentences are similar except for the occurrence of the modals in ii., iii., iv., v., and vi. But conceptually, they are quite different. Due to these reasons, English versions written by Japanese specialists frequently detach themselves from the original Japanese versions. We can say the same in the following sentences:

vii. Capacitors can be combined in either one of two ways.

viii. Capacitors may be combined in either one of two ways.

\subsection{Subjunctive moods}

Native speakers of English choose the following italicized verbs with almost instinctive correctness. For Japanese specialists, however, this is not the case. Many specialists feel just as uncertain about using modals in the following sentences correctly. They know the syntactic structures, but are extremely weak in understanding which sentences make statements fact. In fact, to them, the following four sentences do not seem different in meaning.

i. If the two electrodes are connected externally, a current is established through the wire.

ii. If the two electrodes were connected externally, a current 
would be established through the wire.

iii. If the two electrodes should be connected externally, a current is/would be established through the wire.

iv. If the two electrodes were to be connected externally, a current would be established through the wire.

These phenomena frequently cause English versions written by Japanese to be not only ambiguous but quite different from the original Japanese.

\section{5. Prepositions}

The smallest English words sometimes present the largest problems. This is particularly true of prepositions. As in the use of articles, native speakers of English instinctively know the proper use of prepositions. For Japanese specialists, however, prepositions cause trouble not only because a single preposition can be construed to express several different ideas, but because the context becomes quite different according to the prepositions we use. Consider the following examples. In the Japanese versions, both syntactical and conceptual structures in groups I and II are the same if they are not expressed in a roundabout way.

I. i. Install the outlet on the wall.

ii. Install the outlet in the wall.

II. i. Apply a few drops of oil in the hole.

ii. Apply a few drops of oil into the hole.

The same can be said in the following:

i. The positively charged ions are attracted toward the cathode.

ii. The positively charged ions are attracted to the cathode. The following also should be translated into the same Japanese:

i. The screw was taken out of the can.

ii. The screw was taken from the can.

iii. The screw was taken off the can. 
iv. The screw was taken through the can (after removing the top and bottom).

\section{1. Improper adjectives}

Through the use of modifiers, especially adjectives, the specialist can present facts and ideas in more specific, concrete form. As such words are indispensable in stating exactly what they desire to express, native speakers of English often find Japanese translations strange for example "tender" light instead of "soft" light. This unsuitable adjective often results from Japanese-English Dictionaries. Most Japanese people rely on such dictionaries and are inclined to use an adjective without realizing the proper meaning.

\subsection{Unsuitable subject noun and predicate verb}

The same phenomenon as 2.1. appears in a subject and a verb. The statement made by each noun seldom applies to that noun's grammatical predicate. A Japanese specialist might write, "A single dry-cell moves your clock accurately for one full year." Faulty selection of a verb for the subject often confuses the readers. Native speakers of English instinctively know the correct usages of these items, but for Japanese specialists the case is quite different.

The focus of this short article is not on mutually unrelated structures but on the interaction between and among structurally similar sentences. We must teach them how important it is to master some indispensable parts of English grammatical aspects that usually do occur in technical contexts.

Clearly, a scientific and technical text is not merely a string of sentences. All of them have not only rhetorical value but a hierachical order. The rhetorical competence is an important but undeveloped subject for the Japanese EST practitioners to study. Unless this area is studied, the effective and clear EST discourses also cannot be achieved by Japanese practitioners. 